\title{
Efficacy of Periodontal Stem Cell Transplantation in the Treatment of Advanced Periodontitis
}

\author{
Joo-Young Park, ${ }^{*} \dagger^{1}$ Soung Hoo Jeon, ${ }^{*} \dagger^{1}$ and Pill-Hoon Choung $* \dagger$ \\ *Department of Oral and Maxillofacial Surgery and Dental Research Institute, \\ School of Dentistry, Seoul National University, Seoul, Republic of Korea \\ $\dagger$ Tooth Bioengineering National Research Laboratory, BK21, School of Dentistry, \\ Seoul National University, Seoul, Republic of Korea
}

\begin{abstract}
Periodontitis is the most common cause for tooth loss in adults and advanced types affect $10-15 \%$ of adults worldwide. The attempts to save tooth and regenerate the periodontal apparatus including cementum, periodontal ligament, and alveolar bone reach to the dental tissue-derived stem cell therapy. Although there have been several periodontitis models suggested, the apical involvement of tooth root is especially challenging to be regenerated and dental stem cell therapy for the state has never been investigated. Three kinds of dental tissue-derived adult stem cells (aDSCs) were obtained from the extracted immature molars of beagle dogs $(n=8)$, and ex vivo expanded periodontal ligament stem cells (PDLSCs), dental pulp stem cells (DPSCs), and periapical follicular stem cells (PAFSCs) were transplanted into the apical involvement defect. As for the lack of cementum-specific markers, anti-human cementum protein 1 (rhCEMP1) antibody was fabricated and the aDSCs and the regenerated tissues were immunostained with anti-CEMP1 antibody. Autologous PDLSCs showed the best regenerating capacity of periodontal ligament, alveolar bone, and cementum as well as peripheral nerve and blood vessel, which were evaluated by conventional and immune histology, 3D micro-CT, and clinical index. The rhCEMP1 was expressed strongest in PDLSCs and in the regenerated periodontal ligament space. We suggest here the PDLSCs as the most favorable candidate for the clinical application among the three dental stem cells and can be used for treatment of advanced periodontitis where tooth removal was indicated in the clinical cases.
\end{abstract}

Key words: Dental mesenchymal stem cell; Adult stem cell therapy; Advanced periodontitis; Tooth; Cementum

\section{INTRODUCTION}

Oral diseases are included among the World Health Organization (WHO) definition of chronic diseases, and the associations between oral health status and chronic systemic diseases have been observed recently $(48,49)$. Among them, periodontitis is a periodontal tissue infectious disease and the most common cause for tooth loss in adults. This common disease is characterized by clinical attachment loss, alveolar bone resorption, periodontal pocketing, and gingival inflammation (20). Many researchers have tried to regenerate the periodontal apparatus, including cementum, periodontal ligament, and alveolar bone, but the regenerative treatment of periodontal disease has been a major challenge in clinical periodontics (57).

Conventional regeneration therapies such as guided tissue regeneration (GTR), topical application of enamel matrix derivative (EMD), or various growth factors can partially regenerate periodontal tissues $(8,10,11,14,15$, $27,30)$. The results in clinical applications vary greatly, depending on the different characteristics of the defects or amount of remaining surrounding alveolar bone and PDL. The strategy of periodontal tissue regeneration therapies is to control inflammation and stimulate stem progenitors to regenerate new periodontal tissues. However, the residual stem cells are limited in those patients with periodontitis because of long-term inflammation and limited cell source (38). Especially among many kinds of periodontal defects, apical involvement is known as one of the most challenging states to be regenerated and no satisfactory therapeutic approach is agreed except for tooth extraction $(16,58-60)$.

The aim of this study was to evaluate the effective-

Received February 2, 2010; final acceptance June 15, 2010. Online prepub date: August 18, 2010

${ }^{1}$ These authors provided equal contribution to this work.

Address correspondence to Pill-Hoon Choung, D.D.S., Ph.D., Department of Oral and Maxillofacial Surgery, School of Dentistry, Seoul National University, 28 Yeongeon-dong, Jongno-gu, Seoul, Republic of Korea, 110-749. Tel: +82-2-740-8717; Fax: +82-2-740-8717; E-mail: cph@ plaza.snu.ac.kr 
ness of autologous dental stem cell transplantation for advanced periodontal disease in beagle dogs. The disease model was designed to simulate human advanced periodontitis where one of the tooth roots was floated from the surrounding bone and the tooth was indicated to be removed clinically. Three kinds of autologous dental stem cells were isolated from the extracted immature tooth and the ex vivo expanded dental stem cells were grafted to the defect without scaffold. The results of the tissue regeneration were evaluated by complete regeneration of cementum, alveolar bone, and periodontal ligament, to assess the most appropriate candidate for the future clinical application.

\section{MATERIALS AND METHODS}

\section{Animals}

Eight beagle dogs aged 10 months with $10 \mathrm{~kg}$ body weight were obtained and examined for good systemic and oral health. Animals were housed under conventional conditions with free access to water and food. This study was reviewed and approved by institutional animal care and use committee (No. 070504-5, ilar.snu. ac.kr, IACUC), at Seoul National University, Seoul, Korea.

\section{Generation of Periodontitis Model}

The dogs received plaque control, consisting of brushing twice weekly and application of $0.5 \%$ chlorhexidine gluconate solution, to establish healthy gingival conditions prior to surgical procedures. All surgical procedures were performed under general anesthesia with intravenous injection of zolazepam $(0.3 \mathrm{ml} / \mathrm{kg}$, Zoletil50, Virbac, France) with $2 \%$ Rompun $(0.15 \mathrm{cc} / \mathrm{kg}$, xylazine HCL, Bayer, Germany), and local anesthesia with $2 \%$ lidocaine hydrocholoride with 1:100,000 epinephrine. After clinical assessment of all 40 teeth in eight dogs, the mucoperiosteal flaps were elevated and alveolar bone was removed with surgical bur to create apical involvement defect (Fig. 1A-D). The roots were scaled and planed to remove all periodontal ligament fibers and cementum, then the defects were filled with a rubber base impression material (Zetapuls putty, Zhermack, Badia Polesine, Italy) to induce an inflammatory response and prevent spontaneous tissue repair. After the flaps were repositioned, the wounds were closed with 4-0 silk sutures (Fig. 1E, F). The 3-mm-wide circumferential defect around the mesial root of premolar mimicked floating state isolated from the alveolar bone. This procedure was performed for the right and the left 2nd and 4th mandibular premolars of each dog, whereas the 1st molars had no treatment as representatives of normal periodontal tissues (Fig. 1A). Therefore, 32 defects were created in eight beagle dogs in total.

\section{Canine Stem Cell Culture}

After the extraction of the immature molar tooth, dental pulp, periodontal ligament, and periapical follicle were carefully dissected. The separated tissues were digested in a solution of $3 \mathrm{mg} / \mathrm{ml}$ collagenase type I (Worthington Biochem, Freehold, NJ, USA) and $4 \mathrm{mg} / \mathrm{ml}$ dispase (Boehringer, Mannheim, Germany) for $1 \mathrm{~h}$ at $37^{\circ} \mathrm{C}$. Cell suspensions were cultured in the DMEM (Gibco BRL, Grand Island, NY, USA) supplemented with $10 \%$ FBS (Gibco BRL, Grand Island, NY, USA), $100 \mu \mathrm{mol} /$ $\mathrm{L}$ ascorbic acid 2-phosphate (Sigma, USA), $2 \mu \mathrm{mol} / \mathrm{L}$ glutamine, $100 \mathrm{U} / \mathrm{ml}$ penicillin, and $100 \mu \mathrm{g} / \mu \mathrm{l}$ streptomycin (Biofluids, Rockville, MD, USA). Cell suspensions were incubated at $37^{\circ} \mathrm{C}$ in $5 \%$ carbon dioxide. All primary cells were used in their second or third passage.

\section{Immunocytochemistry}

To identify the putative postnatal stem cells from the cultured cells, expression of STRO-1 was confirmed by immunocytochemistry. The isolated cells from the dental pulp, periodontal ligament, and periapical follicle were seeded on $22 \times 22-\mathrm{mm}$ cover slips in six-well plates $\left(2 \times 10^{4}\right.$ cells/well, NUNC, USA) and cultured for $24 \mathrm{~h}$. After being washed in PBS ( $\mathrm{pH}$ 7.4) and fixed in $3.7 \%$ paraformaldehyde (PFA) for $10 \mathrm{~min}$, the samples were incubated with STRO-1 Ab (1:200, mouse antihuman STRO-1 mAb MAB1038 (R\&D Systems, Minneapolis, MN, USA) for $2 \mathrm{~h}$. The cells were subsequently incubated with secondary $\mathrm{Ab}$ of fluorescence for $1 \mathrm{~h}$. Then the nuclei were stained in DAPI $(2 \mu \mathrm{g} / \mathrm{ml})$ for $30 \mathrm{~min}$.

\section{$R T-P C R$}

Total RNA was prepared by Trizol reagent (Invitrogen, Carlsbad, CA, USA) according to the manufacturer's protocol. The first-strand cDNA was synthesized through a cDNA synthesis kit (Invitrogen, USA). The primer set for PCR included CD146 (sense, 5'-TAC CCC ATT CCT CAA GTC-3'; antisense, 5'-TCA GAC ACA TAG TTC ACC AG-3') and canine GAPDH (sense, 5'-TCT CAA CTA CAT GGT GTA CA-3'; antisense, 5'GGA AAT GAG CTT GAC AAA GT-3'). The PCR reactions were preincubated in a PCR Mastercycler gradient (Applied Biosystems, Carlsbad, CA, USA) at $95^{\circ} \mathrm{C}$ for $3 \mathrm{~min}$ and then cycled 33 times at $95^{\circ} \mathrm{C}$ for $30 \mathrm{~s}$, $55^{\circ} \mathrm{C}$ for $45 \mathrm{~s}$, and $72^{\circ} \mathrm{C}$ for $60 \mathrm{~s}$, then followed by a final 10 -min extension at $72^{\circ} \mathrm{C}$. The products were separated by electrophoresis on a $1 \%$ agarose gel and visualized by UV induced fluorescence.

\section{Flow Cytometric Analysis}

The canine DPSCs, PDLSCs, and PAFSCs were prepared as single cell suspension at about $1 \times 10^{6}$ in their third passage. After trypsin/EDTA digestion, cells were 



\section{$\mathbf{J}$}

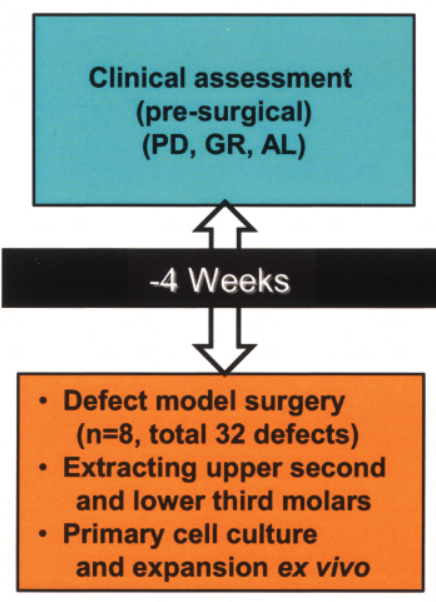



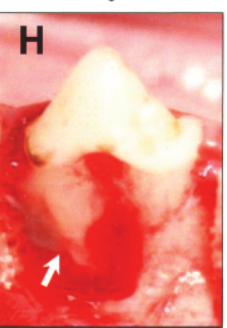

Clinical assessment (diseased) (PD, GR, AL)

Radiological examination

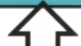

Transplantation



Transplantation

(1) Stem cell transplantation group

( $n=8$, total 24 defects)

(2) Negative control group

( $n=8$, total 8 defects but no stem cell graft)

(3) Positive control group

( $n=8$, total 8 normal teeth)

Figure 1. Generation of periodontitis model in beagle dogs. (A) Schematic illustration of teeth arrangement of control (green) and experimental (pink) group in canine mandible. One of the 1st mandibular molars was the positive control tooth and the negative control (no graft) and three dental stem cell graft teeth were determined randomly among the four premolars. (B, F) Schematic illustration of advanced periodontitis model used in this study. Advanced periodontitis progressed by root apex in the mesial root of canine premolar. (C) Four weeks before the stem cell transplantation, clinical indices were measured and then the mucoperiosteal flap was raised. The healthy periodontium with intact alveolar bone was shown presurgically. The defect with 3-mm depth and width around the root apex was made (D) and foreign impression material was inserted to maintain inflamed state and the flap was closed (E). (G) Four weeks after the defect surgery, clinical indices were measured and then the impression material and granulation tissue were removed. The planed mesial root floating from the surrounding bone is shown (arrow). (H) Approximately $6 \times 10^{6}$ cells of periodontal ligament stem cells (PDLSCs), dental pulp stem cells (DPSCs), and periapical follicular stem cells (PAFSCs) were grafted (arrow) to the defect and covered with mucoperiosteal flap with sutures (I). (J) The timetable of in vivo experimental procedures. Eight beagle dogs with 40 teeth in total were tested with this schedule. Scale bars: $2 \mathrm{~mm}$.

fixed with $4 \%$ PFA for 10 min. After resuspension in $1 \%$ BSA (ICN Biomedicals, Aurora, OH, USA) blocking buffer, the cells were incubated with primary STRO$1 \mathrm{Ab}$ (experimental cells; $1 \mu \mathrm{g} / \mathrm{ml}$ ) or PBS (control cells) at $4^{\circ} \mathrm{C}$ for $3 \mathrm{~h}$, followed by secondary $\mathrm{Ab}$ of fluorescence at room temperature for $1 \mathrm{~h}$. The percentage of STRO-1-positive staining DPSCs, PDLSCs, and PAFSCs were measured with a FACS Calibur flow cytometry (Becton Dickinson Immunocytometry Systems, San Jose, CA, USA). For analysis of STRO-1-positive cells, the percentage of the cells positioned in the right side of the M1 gate was measured. The M1 gate was defined as a peak of negative control cells without primary antibody. The relatively STRO-1-positive cells were calculated 
from the percentage of the experimental cells minus the percentage of the control cells.

\section{Multipotent Differentiation}

Differentiation potential of the aDSCs to undergo mineralization and adipogenesis was examined, as previously described (32). For mineralization, $1 \times 10^{4}$ PDLSCs, DPSCs, and PAFSCs were plated in a $60-\mathrm{mm}$ dish and cultured in optimal culture medium for 3 days. Then cells were incubated with optimal culture medium supplemented with $5 \mathrm{mM} \beta$-glycerophosphate and $10 \mathrm{nM}$ dexamethasone (Sigma, St. Louis, MO, USA) for 2 weeks to induce mineral formation. Mineral nodule formation was observed by staining the cultures with $40 \mathrm{mM}$ Alizarin red $(\mathrm{pH} 4.2)$.For adiopogenesis, $3 \times 10^{4}$ cells were plated in a $60-\mathrm{mm}$ dish and cultured in optimal culture medium for 3 days. The medium was replaced with adipogenic medium (StemPro, Gibco BRL, Grand Island, NY, USA) and cultured for 1 week. The adipogenic cultured cells were fixed in $70 \%$ ethanol for $10 \mathrm{~min}$ and stained with fresh Oil red $\mathrm{O}$ solution (Sigma, USA) for $2 \mathrm{~h}$.

\section{Autologous Dental Stem Cell Transplantation}

Four weeks after the generation of periodontitis defect, clinical assessment was made for all 40 teeth. Each beagle dog had all of the five groups of teeth (Fig. 1A). One of the 1st mandibular molars was positive control group and the other premolar sites were randomly determined for specific cell graft group. The five groups were: (a) positive control group-no surgical intervention $(n=8)$, (b) negative control group-periodontal defect but no stem cell graft $(n=8)$, (c) PDL stem cell graft group $(n=8),(\mathrm{d})$ dental pulp stem cell graft group $(n=8)$, and (e) periapical follicular stem cell group $(n=$ 8) (Fig. 1).

The mucoperiosteal flaps were raised to expose the inflamed apical involvement defects, and then the impression materials and granulation tissues were removed with curettes and the root surfaces were scaled and planed for groups (b), (c), (d), and (e) (Fig. 1G). For the negative control group (b), the mucoperiosteal flap was closed without stem cell graft.

Approximately $6 \times 10^{6}$ cells of PDLSCs, DPSCs, and PAFSCs were grafted to each defect and closed with sutures (Fig. 1H, I). The number of the aDSCs was decided from the fact that the cellular pellet should cover the denuded root surface thoroughly and filled the defect. The number $6 \times 10^{6}$ was decided based on several preliminary experiments to examine the minimal number of the cells that satisfy these necessary conditions. The hemocytometer with trypan blue dye $(0.4 \%$, Gibco, Invitrogen, Carlsbad, CA, USA) was used for selective counting of the viable stem cells for transplantation. The transplanted aDSCs were characterized in vitro as described and these results are shown in the Results section.

All animals received $500 \mathrm{mg}$ of amoxicillin three times daily for 7 days (mixed with food), and their mouths were washed daily with $0.5 \%$ chlorhexidine digluconate for 5 days.

\section{Clinical Evaluations}

Clinical assessments, probing depth (PD), gingival recession (GR), and attachment loss (AL) were measured on all experimental teeth pretransplantation (week $-4)$ and peri- and posttransplantation of both week 0 and week 8 (Fig. 1J, Fig. 2A, B). The values were established with a Williams periodontal probe (PQW6, HuFriedy, Chicago, IL, USA).

\section{D Micro-CT Analysis}

The sample of alveolar bone containing premolars was firstly trimmed to proper size for the analysis chamber of the micro-CT device (SkyScan1172 high-resolution micro-CT, Kontich, Belgium), and then the sample was mounted on a turntable that could be shifted automatically in the axial direction. Six hundred projections were taken over 180 of object rotation $\left(0.3^{\circ}\right)$. The X-ray shadow projections were digitized as $1024 \times 1024$ pixels with 4096 brightness gradations (12 bit) for cooled camera or 256 gradations ( 8 bit). The spatial resolution obtained was $15 \mu \mathrm{m}$.

\section{Histological Examination}

At 8 weeks after stem cell transplantation, all animals were sacrificed, and the canine mandibles were harvested and fixed in 4\% PFA for $96 \mathrm{~h}$. The premolars were cut buccolingually in the midroot region and the heights of new bone formation were measured by the Williams periodontal probe. The distance from the top of newly formed bone to the point $3 \mathrm{~mm}$ deeper than the root tip was measured (Fig. 2). Each sample was measured by three different specialists and the mean values were calculated. Half of the sample was embedded in polymethylmethacrylate as separated blocks using Osteobed (Polysciences, Warrington, PA, USA) without decalcification. The blocks were trimmed using a diamond saw using the Exakt equipment (Exakt, BS3000N, Oklahoma City, OK, USA). The specimens were then ground to a final thickness of approximately $40 \mu \mathrm{m}$ (Exakt, MG-4000, USA) and stained with H\&E and Masson's trichrome (MT) and examined under light microscope. (Olympus U-SPT, BX51, Japan).

The other half of the sample was decalcified in $10 \%$ EDTA for 8 weeks and embedded in paraffin. Serial bucco-lingual sections $(4 \mu \mathrm{m})$ were stained with $\mathrm{H} \& \mathrm{E}$ or incubated with the anti-CEMP1, anti-STRO-1, and DAPI. Immunohistochmical stained samples were im- 

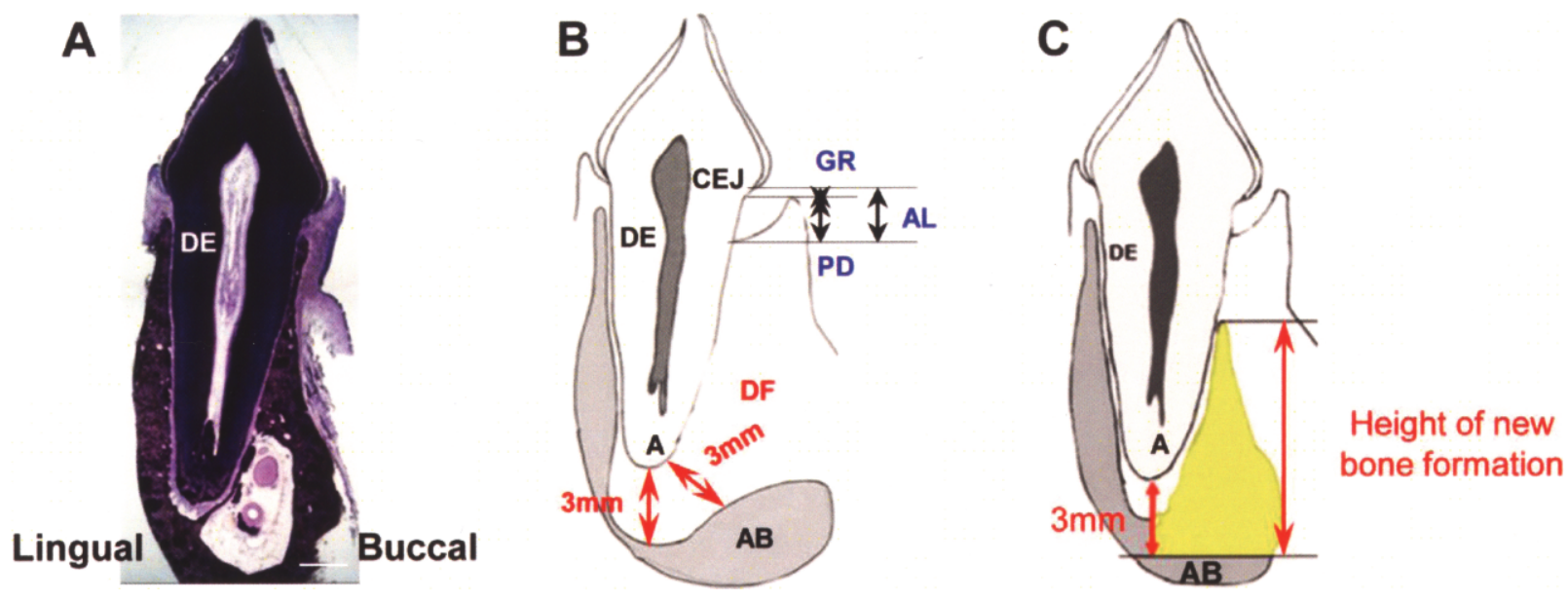

Figure 2. Advanced periodontitis model and evaluation methods for periodontal regeneration. (A) Longitudinal histological section (buccolingual) of the normal periodontal tissue in canine tooth by H\&E staining. Scale bar: $2 \mathrm{~mm}$. (B) Schematic illustrating the advanced periodontitis model with 3-mm bone defect around the apex. Clinical assessment indices were: GR is the height from $\mathrm{CEJ}$ to the margin of gingiva; PD is the depth of periodontal pocket; AL is the length from CEJ to the bottom of the pocket (the bottom of the pocket was below CEJ in this study, AL is equal to the GR plus PD). (C) The height of new bone formation was defined as the length from the point $3 \mathrm{~mm}$ far from the apex to the highest point of alveolar bone crest. Abbreviations: A, root apex; AL, attachment loss; AB, alveolar bone; DE, dentin; DF, defect; CEJ, cemento-enamel junction; GR, gingival recession; PD, probing depth.

aged using a LSM 510 META confocal laser scanning (Carl Zeiss, Oberkochen, Germany).

\section{Molecular Cloning, Expression, and Ab Fabrication of $r h C E M P 1$}

The nucleotide sequence of CEMP1 refers to GenBank Acceesion Number AY584596 (1). Recombinant clones were constructed with a pGEM ${ }^{\circledR}$-T Easy vector (Promega, Madison, WI, USA) for cloning of a CEMP1 transcript. All recombinant DNA researches were included in RG1 based on the NIH guidelines for research involving recombinant DNA molecules. A sense (5'CTC GAG AAT GGG CAC ATC AAG CAC TGA-3') and an antisense (5'-GAA TTC CCC CAT TAG TGT CAT CCT G-3') primer were designed to fuse pRSET vector (Invitrogen, Carlsbad, CA, USA) for inducible bacterial expression. A $50 \mu \mathrm{l}$ reaction was set up using the following PCR conditions: denaturation at $94^{\circ} \mathrm{C}$ for $10 \mathrm{~min}$, followed by 35 cycles of $94^{\circ} \mathrm{C}$ for $30 \mathrm{~s}, 65^{\circ} \mathrm{C}$ for $30 \mathrm{~s}$, and $72^{\circ} \mathrm{C}$ for $1 \mathrm{~min} 15 \mathrm{~s}$, with an additional final elongation step of $72^{\circ} \mathrm{C}$ for $8 \mathrm{~min}$. The identity of the PCR products was confirmed by sequencing (data is not shown). The pRSET vector contains an N-terminal polyhistidine (6xHis) tag for further purification with nickel-chelating resin and detection with an anti-His $\mathrm{Ab}$ (cell signaling, 2365, Danvers, MA, USA). The resultant plasmid was introduced into BL21 (DE3) expression host $E$. coli strain (Invitrogen) and this construction was grown at $37^{\circ} \mathrm{C}$ in LB medium containing $100 \mu \mathrm{g} / \mathrm{ml} \mathrm{am}-$ picillin to OD of 0.4 at $600 \mathrm{~nm}$. IPTG was added to a final concentration of $1.0 \mathrm{mM}$ and the bacterial culture was incubated at $37^{\circ} \mathrm{C}$. The cells were harvested after 8 $\mathrm{h}$ by centrifugation and the cell pellet was lysed and processed as described elsewhere (53). Recombinant CEMP1 protein purification was performed by $\mathrm{Ni}^{2+}$ NTA affinity resin column (Quiagen, Germantown, MD, USA). Determination of protein purity was performed by a $12 \%$ SDS-PAGE.

Affinity purified recombinant CEMP1 sized $M_{r}$ 30,000 was excised from the gel and the protein was eluted by electrophoresis from the gel slices (50). Polyclonal $\mathrm{Ab}$ was produced and purified in New Zealand white rabbits as reference (29). Ab production was monitored by immunoblot and purification was performed by protein A-sepharose chromatography (Quiagen, Germantown, MD, USA).

\section{Statistical Analysis}

All values were expressed asmean \pm SD. To test the statistically significant differences among all groups, one-way ANOVA was used. A value of $p<0.001$ was regarded as statistically significant, which was adjusted by Bonferroni method to allow for the multiple comparisons.

\section{RESULTS}

\section{Isolation and Characterization of aDSCs}

We isolated and expanded three kinds of aDSCs from the immature upper second molar and lower third molar of each beagle dog. Root development of those molars 
was not completed, as the dogs were about 10 months old and periapical follicle existed as well as periodontal ligament and dental pulp. The isolated cells formed single cell-derived colonies and most of the cells retained their fibroblastic spindle shape (Fig. 3A, lower left panel). The expression of CD146, one of the surface markers of MSCs (13), was determined by RT-PCR with the designed primers of canine CD146 and the transcripts were detected in all three kinds of aDSCs (Fig. 3B). The isolated cell populations expressed the cell surface molecule STRO-1, another putative MSC marker $(55,61)$, in immunofluorescent imaging (Fig. 3C). The STRO-1 expression was stained in green fluorescence and distributed mainly on the surface of the aDSCs (Fig. 3C, white arrows).

Flow cytometric analysis showed ex vivo expanded aDSCs contained approximately $47.7 \%, 41.1 \%$, and $45.2 \%$ of STRO-1-positive cells in PDLSCs, DPSCs, and PAFSCs, respectively (Fig. 3D). The percentage of STRO-1-positive cells was determined by relative intensity of STRO-1 antibody binding cells. The percentage of control cells at the right side of M1 gate (black) was deducted from the percentage of the experimental cells at the right side of $\mathrm{M} 1$ gate (red).

Two-week-old culture in the mineralization induction condition showed Alizarin red-positive condensed nodules in all three aDSCs (Fig.3E, upper panels). The potential of aDSCs to differentiate into adipocytes was shown by 1 week of culture with the adipogenesis induction condition. Oil red O-positive lipid clusters were identified in all three aDSCs (Fig. 3E, lower panels). These results suggest that all of the transplanted canine aDSCs in this study possessed the ability to differentiate into developmentally diverse phenotypes.

\section{Generation of Periodontitis in Beagle Dog}

All surgeries went well and clinical healing was uneventful without significant inflammation in all defects after operation. No adverse reactions, such as toxic signs, suppuration, and formation of neoplasm were observed throughout the experimental period. The control and experimental teeth were designed to exist in one mandible of one animal, as comparison among the three autologous aDSCs in one animal is necessary (Fig. 1A). One premolar space remained between the two experimental teeth (P2 and $\mathrm{P} 4)$ to prevent propagation of inflammation and migration of the stem cells. To determine whether the advanced periodontitis was reproduced clinical status of the periodontal tissues was assessed by commonly used clinical indices, such as probing depth (PD), gingival recession (GR), and attachment loss (AL) (Fig. 2A, B). In the early stage of periodontitis, PD could reflect the degree of inflammation in periodontal tissues, as gingival tissue could be intact. As periodon- titis progresses, AL is considered to be a more appropriate parameter to assess the periodontal status as it implicates destruction of all periodontal apparatus, alveolar bone, cementum, and periodontal ligament. At the time point of -4 weeks, there was no significant difference among the five groups in $\operatorname{AL}(F=1.829, p=0.152)$. Immediately before the stem cell graft was performed, AL increased to $6.70-7.90 \mathrm{~mm}(F=2.712, p=0.067)$ with deep periodontal pocket $4.88-5.05 \mathrm{~mm}(F=0.135, p=$ 0.938) in four groups of teeth, meaning statistically equal advanced periodontitis was involved at each mesial root (Table 1).

\section{aDSCs-Mediated Periodontal Tissue Regeneration}

We hypothesized that aDSCs transplantation should be effective to treat inflammation and regenerate periodontal tissues even in the advanced periodontitis. Apical involvement of root can be considered as one of the indications of tooth removal in human clinical cases, as the surrounding bone is absent and blood supply is interrupted by granulation tissue. Besides, the ability to regenerate periodontal tissue in such condition may be different depending on which kind of aDSC was grafted. To test these hypotheses, clinical periodontal indices assessment, histological analysis, and micro-CT evaluation were used for the three kinds of aDSC graft groups. Two months after the stem cell graft, AL decreased from 7.05 to $4.03 \mathrm{~mm}$ so that $3.02 \mathrm{~mm}$ attachment gain was shown in the PDLSCs group, while there was only a $0.35 \mathrm{~mm}$ gain in the DPSCs group (Table 1). The negative control group without treatment showed an increase of AL from 7.90 to $8.30 \mathrm{~mm}$, indicating limited self-regeneration and proved that the periodontitis defect suggested in this study was the critical size defect in vivo. Statistical analysis indicated that PDLSC graft significantly improved periodontal tissue regeneration in comparison with DPSC graft group as well as the untreated control group $(p<0.0001)$ (Table 1).

In histological analysis, the PDLSC grafted defect showed regenerated alveolar bone crest (Fig. 4A, left panel, black arrow) and deposited cementum (Fig. 4A, right panel, white arrows). Incremental lines of regenerated cementum over the root planed dentin were observed. Sharpey's fibers, which have a crucial role of connecting a tooth to the surrounding alveolar bone (54), emitted from the regenerated alveolar bone (Fig. 4A, right upper panel, black arrows). Cellular cementum was also regenerated at the root apex and embedded cementocytes were shown (Fig.4A, right lower panel, white arrows). Negative control tooth (Fig. 4B, right upper panel) shows denuded dentin surface without tissue attachment but only with surrounding granulation tissue, compared to the positive control tooth (Fig.4B, left upper panel). The normal periodontium showed acellular 
A

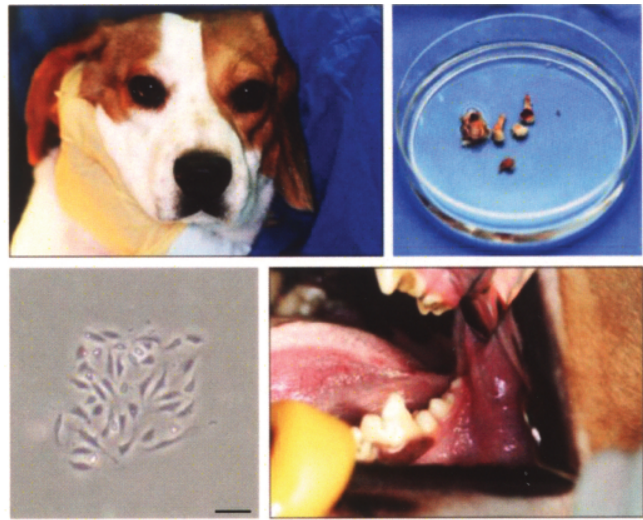

B



C
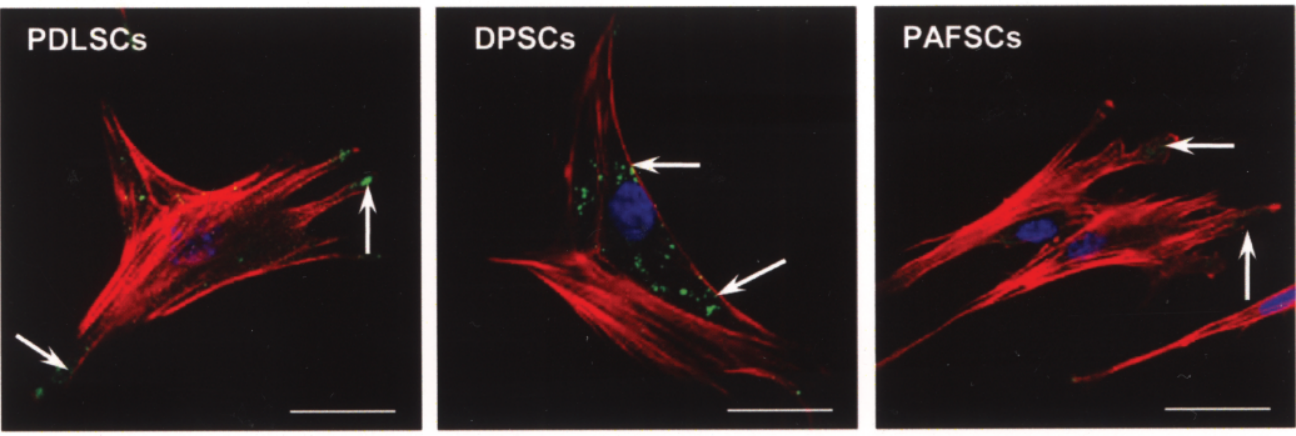

D
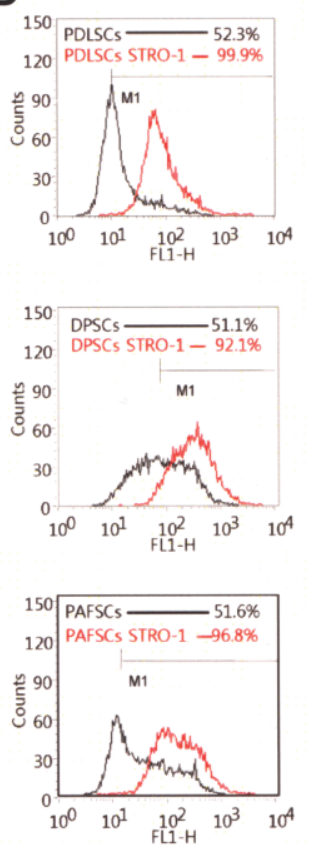
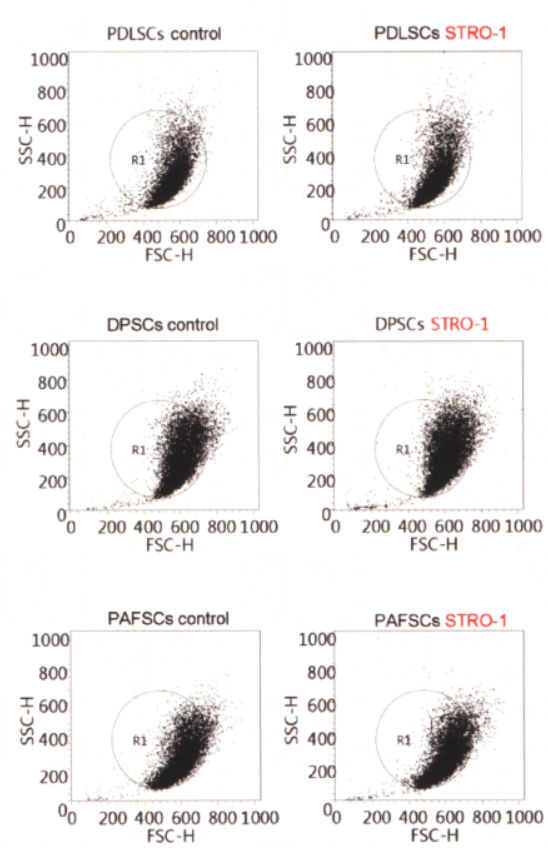

E
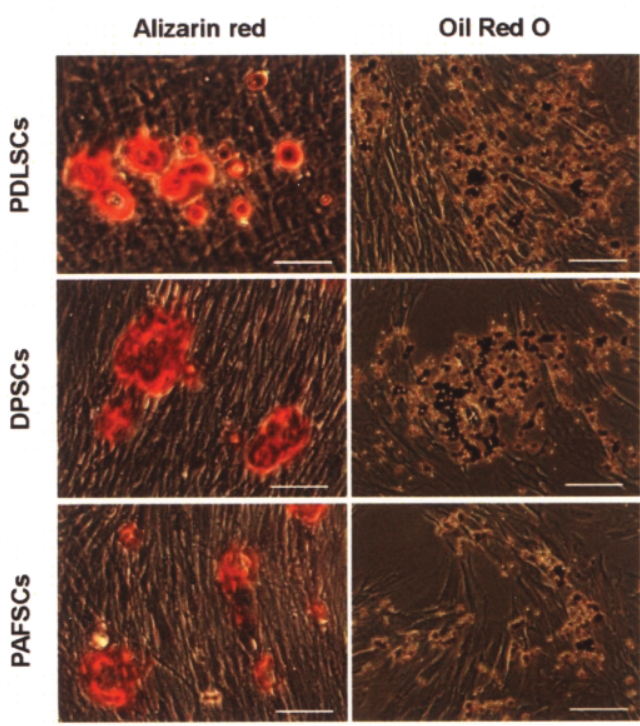

Figure 3. Isolation and characterization of canine dental stem cells. (A) Autologous primary dental stem cells were isolated from the three kinds of dental tissues, PDLSCs, DPSCs, and PAFSCs, in lower immature 3rd molars or upper 2nd molars. The dental stem cells from single colony showed fibroblast-like cells under light microscope. The black scale bar was $80 \mu \mathrm{m}$. (B) RT-PCR showed presence of 510 bp size CD146 and 800 bp size canine GAPDH. (C) Immunocytochemical staining using STRO-1, an early mesenchymal progenitor marker, in three kinds of dental stem cells was positive in green (arrows). Cytoskeleton was visualized with phalloidine in red and DAPI-stained nuclei are shown in blue. Scale bars: $20 \mu \mathrm{m}$. (D) Flow cytometric analysis showed ex vivo expanded aDSCs contained about $47.7 \%, 41.1 \%$, and $45.2 \%$ of STRO-1-positive cells in PDLSCs, DPSCs, and PAFSCs, respectively. (E) Multipotent differentiation of three kinds of aDSCs in mineralization (upper three panels) and in adipogenesis (lower three panels) induction conditions. Alizarin red staining showed calcified nodule formation in red following 2 weeks of mineralization induction. Oil red O staining showed lipid droplet following 1 weeks of adipogenesis induction. Scale bars: $500 \mu \mathrm{m}$. 
Table 1. Clinical Assessment of Periodontal Status

\begin{tabular}{|c|c|c|c|c|c|c|c|c|c|}
\hline \multirow[b]{2}{*}{ Group } & \multicolumn{3}{|c|}{-4 Weeks* } & \multicolumn{3}{|c|}{-0 Weeks $\dagger$} & \multicolumn{3}{|c|}{ +8 Weeks } \\
\hline & PD & GR & $\mathrm{AL}$ & PD & GR & $\mathrm{AL}$ & PD & GR & $\mathrm{AL}$ \\
\hline Control (+) & $2.10 \pm 0.10$ & 0 & $2.10 \pm 0.10$ & $2.30 \pm 0.10$ & $0.08 \pm 0.08$ & $2.30 \pm 0.10$ & $2.30 \pm 0.10$ & $0.2 \pm 0.14$ & $2.50 \pm 0.10$ \\
\hline Control (-) & $2.10 \pm 0.20$ & 0 & $2.10 \pm 0.20$ & $5.00 \pm 0.50$ & $3.00 \pm 0.80$ & $7.90 \pm 0.90$ & $5.20 \pm 0.10$ & $3.10 \pm 0.70$ & $8.30 \pm 0.70$ \\
\hline PDLSCs & $2.01 \pm 0.14$ & 0 & $2.01 \pm 0.14$ & $5.05 \pm 0.58$ & $2.00 \pm 0.51$ & $7.05 \pm 0.76$ & $2.88 \pm 0.75$ & $1.15 \pm 0.30$ & $4.03 \pm 0.84$ \\
\hline DPSCs & $2.05 \pm 0.14$ & 0 & $2.05 \pm 0.14$ & $4.88 \pm 0.53$ & $1.73 \pm 0.35$ & $6.60 \pm 0.59$ & $4.54 \pm 0.41$ & $1.61 \pm 0.29$ & $6.15 \pm 0.58$ \\
\hline PAFSCs & $2.04 \pm 0.19$ & 0 & $2.04 \pm 0.19$ & $5.04 \pm 0.66$ & $1.60 \pm 0.50$ & $6.70 \pm 0.80$ & $3.85 \pm 0.80$ & $1.20 \pm 0.50$ & $5.00 \pm 0.60$ \\
\hline
\end{tabular}

Data are expressed as mean $\pm \mathrm{SD}(\mathrm{mm})$. The differences of PD and $\mathrm{AL}$ at each time point among five groups were analyzed using one-way ANOVA with multiple comparisons. AL, attachment loss; GR, gingival recession; PD, probing depth; PDLSCs, periodontal ligament stem cell; DPSCs, dental pulp stem cell; PAFSCs, periapical follicular stem cell transplantation groups.

*At the time point of -4 weeks, there was no significant difference among five groups in $\operatorname{AL}(F=1.829, p=0.152)$.

$\dagger$ At the time point of 0 weeks, there was no significant difference among four groups in $\mathrm{PD}(F=0.135, p=0.938)$ and $\mathrm{AL}(F=$ 2.712, $p=0.067$ ).

$\ddagger$ At the time point of 8 weeks, the differences of $\mathrm{PD}(F=16.872, p<0.0001)$ and $\mathrm{AL}(F=43.398, p<0.0001)$ among the five groups were statistically significant.

cementum (C), periodontal ligament (gray arrows), and alveolar bone $(\mathrm{AB})$ in $\mathrm{H} \& \mathrm{E}$ and MT staining (Fig. 4B, lower panels). The regenerated $\mathrm{AB}$ and $\mathrm{C}$ were shown in PAFSC grafted tooth (Fig. 4C), where the end of emitting Sharpey's fibers of periodontal ligament buried (Fig. 4C, upper panels, black arrows). Peripheral nerve ingrowth and angiogenesis were observed inside the PDL space (Fig. 4C, lower panels).

To determine the amount of regenerated hard tissue more precisely, calcified histological sections were prepared (Fig. 4D, 4E). Quantitative analysis of height of new bone formation following the definition suggested (Fig. 2C) showed significantly higher bone was regenerated in the PDLSCs group $(p<0.0001)$ than in the DPSCs group as well as the negative control group (Fig. 4F).

Micro-CT was taken to further compare the amount of alveolar bone formation. The images were reconstructed in 3D morphometry (Fig. 5A-E). The positive control group showed the tooth with normal alveolar bone height with intact bony surrounding at apex and root bifurcation in 3D and buccolingual slice cut (Fig. $5 \mathrm{~A}$ ), while the negative control group showed floating mesial root without bony housing and buccal bone loss (Fig. 5B). New bone formation was observed in the PDLSCs and PAFSCs graft groups (Fig. 5C, D). The remaining defect of the DPSCs group was almost the same as the defect seen in the negative control group (Fig. 5E).

To analyze the net volume of the regenerated alveolar bone, the volume of tooth was subtracted from the integrated volume of the selected areas of the periodontal defect or the integrated volume of the regenerated alveolar bone. The calculated volumes were called defect volume (TV) and newly formed bone volume (BV), respectively. The volume ratio was highest at $82.8 \pm 7.9 \%$ in the PDLSCs group and lowest at $50.8 \pm 9.6 \%$ in the DPSCs group (Fig. 5F, Table 2).

\section{Generation of Anti-rhCEMP1 Antibody and Immunolocalization in the Regenerated Periodontal Tissues}

The recombinant vector of PCR CEMPl transcript with pRSET vector was designed and cloned for inducible bacterial protein expression (Fig. 6A). The insertion of CEMP1 DNA size $0.75 \mathrm{~kb}$ to the vector was confirmed by double restriction enzyme cutting, XhoI and EcoRI in 1\% argarose gel (Fig. 6B). Coomassie bluestained gel and immunoblotting with anti-His antibody showed $30 \mathrm{kDa}$ size recombinant CEMP1 protein production in the IPTG (isopropyl-D-thiogalactopyranoside)induced condition (Fig. 6C, D). Purified anti-rhCEMP1 polyclonal antibody showed immunospecificity with rhCEMP1 protein size $30 \mathrm{kDa}$ (Fig. 6E). Immunolocalization of the rhCEMP1 protein in dental stem cells showed intense immunoreaction localized to the cell cytoplasm and nucleus in PDLSCs (Fig. 6F). PAFSCs showed less reactivity than PDLSCs and control cell ACHN showed largely negative (Fig. 6G, and ACHN data not shown).

Immunolocalization of rhCEMP1 in histological section revealed strong expression at the cementoid phase of cellular cementum and inside the PDL space neighboring alveolar bone in the normal periodontium (Fig. $6 \mathrm{H}$, upper two lines, red fluorescence). Alveolar bone and dentin were largely negative. STRO-1-positive cells were shown with green fluorescence in the normal PDL space (Fig. 6H, upper two lines) and it demonstrated the existence of the progenitor cells. Some proportion of STRO-1-positive cells expressed rhCEMP1 in the merged image (Fig. 6H, upper two lines, the most left 
panels). On the other hand, in the regenerated periodontium, STRO-1 expression was decreased, indicating possible differentiation of the progenitor cells into cementoblast, fibroblast, and other lineage cells (Fig. 6H, lower two lines). rhCEMP1 expression was less but positive in the regenerated cementum and PDL space and expression in the PDL space near the alveolar bone was espe- cially intense (Fig. 6H, lower two lines, the second left panels).

\section{DISCUSSION}

In this study, canine adult dental stem cells, PDLSCs, DPSCs, and PAFSCs were isolated and proved to have similarity to other mesenchymal stem cells, such as col-
A

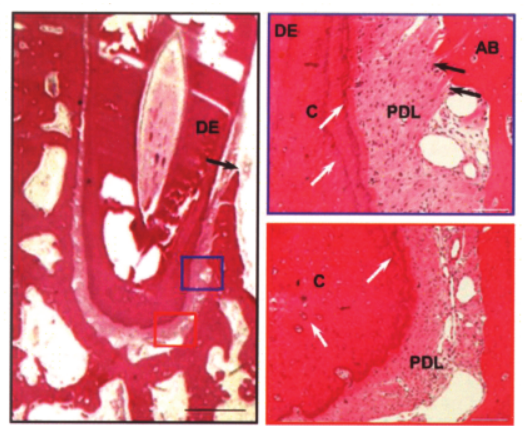

B
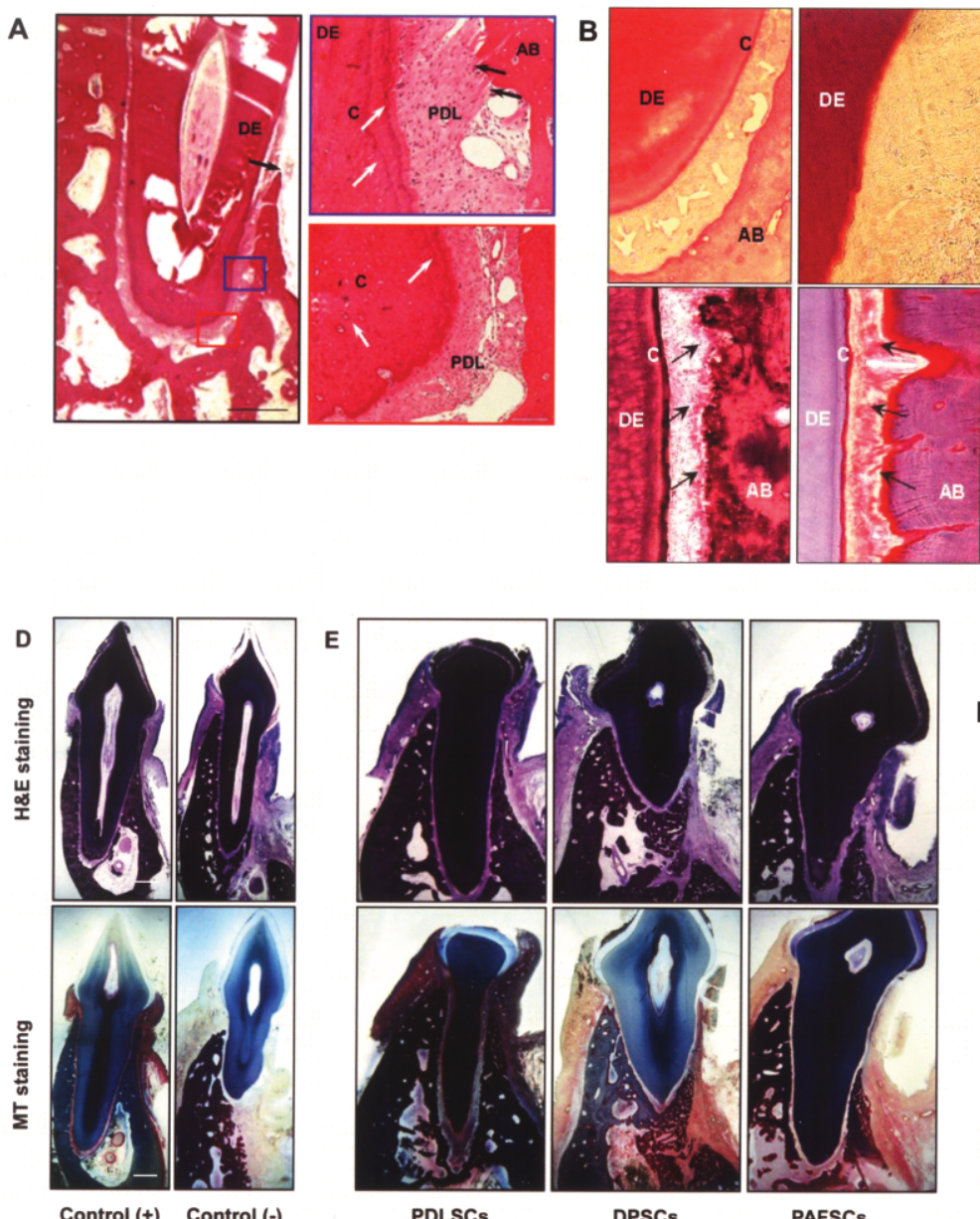

E

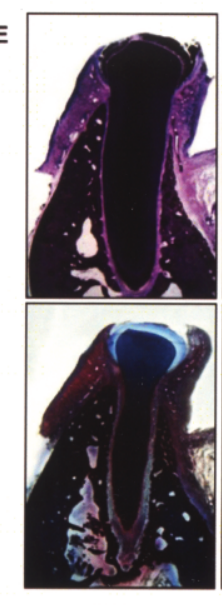

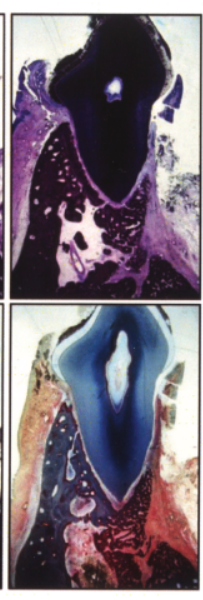

DPSCs

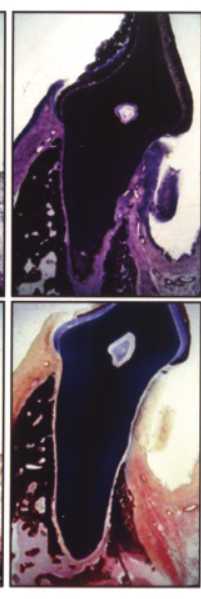

PAFSCs c

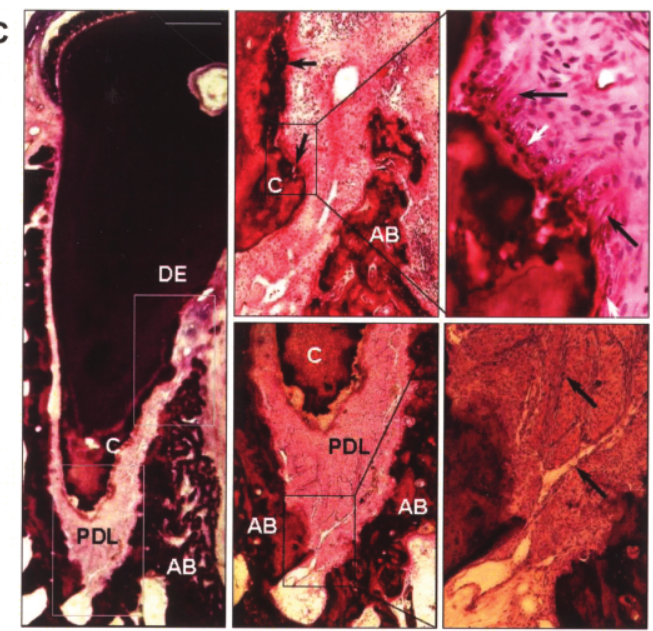

$\mathbf{F}$

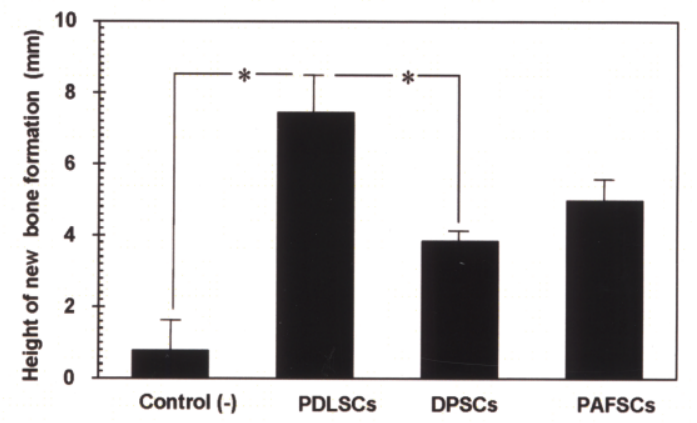

Figure 4. Regeneration of periodontal tissues in histology. (A) H\&E staining of decalcified histological section showed regenerated alveolar bone crest (black arrow) in the PDLSC grafted group (40×). Cellular cementum (C) was deposited, forming incremental lines (white arrows) over the root planed dentin (DE). Black arrows indicate periodontal ligaments emitting from the regenerated alveolar bone (AB) (blue box; 100×). Cellular cementum was also regenerated at the root apex (white arrow, red box; 100×); embedded cementocytes are shown by white arrow. Black scale bar: $1 \mathrm{~mm}$; white scale bars: $0.1 \mathrm{~mm}$. (B) The decalcified root apex of positive control (normal periodontal tissue) and negative control (defect without stem cell graft) in H\&E staining (upper). Negative control tooth (right) showed denuded dentin surface (DE) without tissue attachment but only with surrounding granulation tissue. The calcified section of the normal root surface showed typical Sharpey's fibers (black arrows) in H\&E (lower left; 40×) and MT (lower right; 40×) staining. Scale bars: $0.1 \mathrm{~mm}$. (C) Acellular cementum (C) was deposited over the root planed dentin in the PAFSCs graft group, where the end of emitting Sharpey's fibers of periodontal ligament were buried (black arrows, upper panel, 40× 100×). Peripheral nerve ingrowth and angiogenesis were observed inside the PDL space (black arrows, lower panel, $40 \times, 100 \times$ ). Scale bar: $1 \mathrm{~mm}$. (D) Gross histological assessment of positive (left) and negative (right) control teeth. Negative control tooth showed external root resorption. (E) PDLSC grafted tooth showed highest alveolar bone formation with cementum regeneration and PDL bridging. Scale bars: $2 \mathrm{~mm}$. (F) Quantitative analysis of height of new bone formation. The differences among the four groups were statistically significant $(F=36.278, p<0.0001)$. Data are expressed as mean $\pm \mathrm{SD}(\mathrm{mm})$. $* p<0.001$ was regarded as statistically significant. Control group and PDLSCs group: $p<0.0001$, PDLSCs group and DPSCs group: $p<0.0001$. Abbreviations: $\mathrm{AB}$, alveolar bone; DE, dentin; C, cementum; PDL, periodontal ligament. 

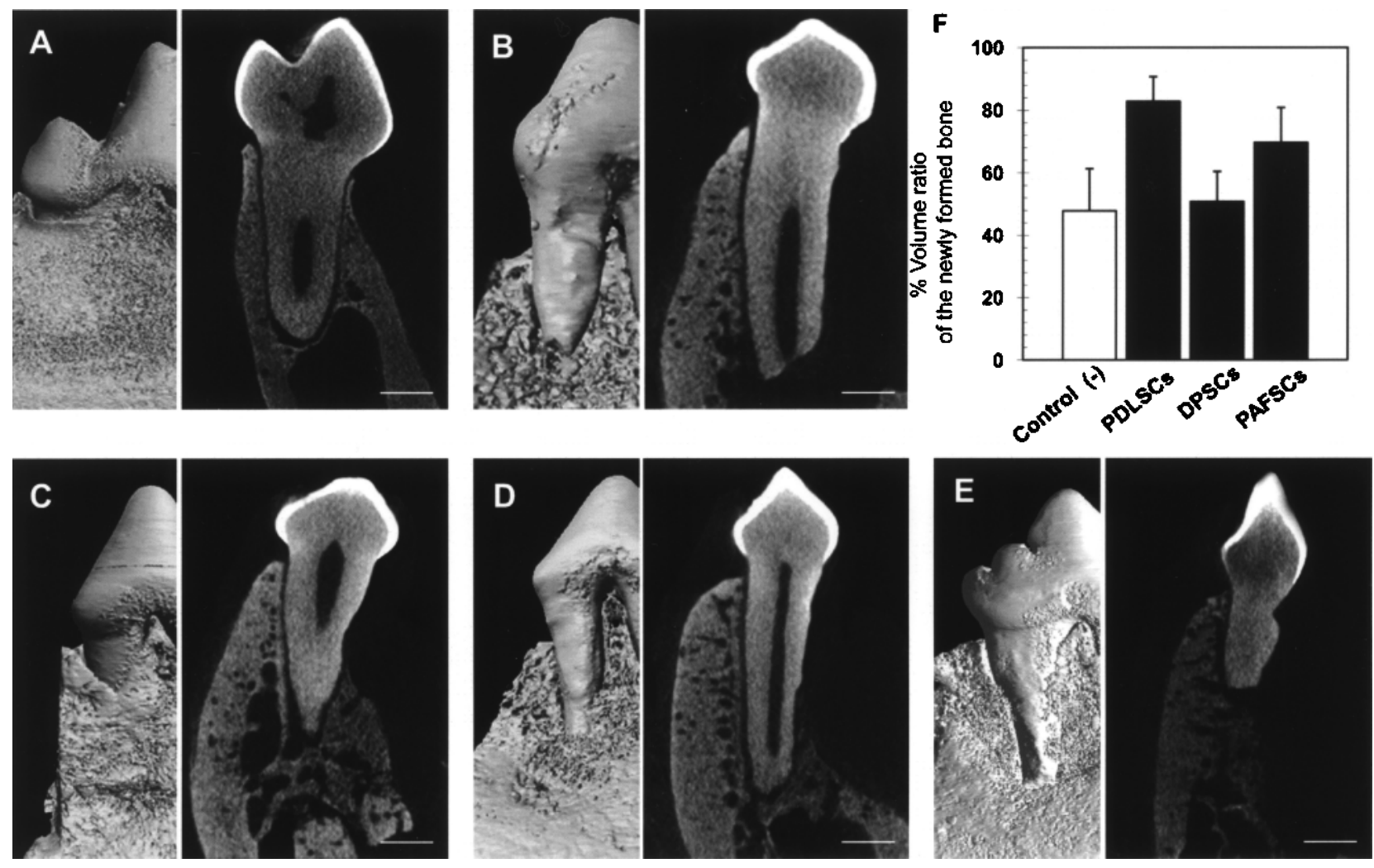

Figure 5. Micro-CT images of 3D reconstructed sample and single slice cut. The positive control group (A) showed the tooth with normal alveolar bone height with intact bony surrounding at apex and root bifurcation, while the negative control group (B) showed floating mesial root without bony housing and buccal bone loss. New bone formation was observed in the PDLSCs (C) and PAFSCs (D) transplantation groups. The remaining defect of DPSCs (E) group was almost the same as the defect seen in the negative control group (B). Comparison of the newly formed bone volume among the groups was shown by the ratio (F) of the newly formed bone volume (BV) to the imaginary defect volume before transplantation (TV). Scale bars: $2 \mathrm{~mm}$.

ony forming ability, CD146, and STRO-1 expression. They also showed regenerating capacity for neighboring and nonneighboring tissues with their multipotency $(13,26,27,32,37,41,42,51,55,61)$. The differences among these aDSCs were compared in vitro in our previous study (32) and the result was that PDLSCs made more calcium nodules and showed higher ALP activity in the mineralized conditioned medium than DPSCs and PAFSCs, while PAFSCs showed higher colonogenic efficiency and proliferation rate. Our hypothesis started from these in vitro results, that aDSCs-mediated periodontal regeneration might be effective to treat advanced periodontitis but the regenerating capacity should be different among the three aDSCs. Our observations in this study indicated that PDLSCs and PAFSCs could both regenerate the periodontal tissues in the advanced periodontitis model but PDLSCs were the best candidate for dental stem cell therapy among the three aDSCs populations. The amount of alveolar bone regeneration was confirmed by measuring the height of new bone formation in histological section, and the evidence was rein- forced by micro-CT images and the calculated volume ratios of 3D reconstruction. Regeneration of Sharpey's fibers in the PDLSCs and PAFSCs transplantation group was observed by $\mathrm{H} \& \mathrm{E}$ and MT staining in the histological sections with and without decalcification. New cementum was shown by immunolocalization of rhCEMP1 as well as by the conventional histological staining methods.

The treatment modalities known to improve periodontal regeneration, such as xenogenic bone particle graft, growth factors such as TGF- $\beta$, BMP-2, and PDGF graft with guided bone regeneration were reported to help form the new alveolar bone $(8,10,11,14,15,28,31)$, but the clinical results were generally unsatisfactory. The reasons of the failure are due to, firstly, insufficient periodontal attachment originated from the cementum and Sharpey's fiber and, secondly, inflammatory disease characteristics of periodontitis. Cementum is the outmost layer lining a dental root and contains the end of Sharpey's fiber in periodontal ligament to support the tooth when it functions. However, granulation tissues and inflammatory mediators destruct the periodontal at- 
tachment and limit the capacity of periodontium for regeneration (39). However, certain kinds of MSCs transplantation can supply large numbers of necessary cells to the disease site and increase its regenerative capacity (21). Besides, they can differentiate into the desired tissues, such as cementum, alveolar bone, and Sharpey's fibers. In this study, canine autologous aDSCs, which were successfully isolated from the immature molars, were transplanted into the advanced periodontitis model and PDLSCs showed excellent treatment results histologically, morphologicaly, and clinically. Interestingly, peripheral nerve ingrowth and angiogenesis were observed at the regenerated PDL space, which is essential for revitalizing and functioning of teeth. Our study implicated that aDSCs transplantation replenished necessary cell reservoir and generated some of the new tissues as well as helped host progenitor cells to differentiate into the desirable cell types. Immunomodulatory and anti-inflammatory effects of MSCs were also expected in $\operatorname{aDSCs}(9,45,56,63)$ and they may have influenced the advanced periodontitis environment in this study.

There have been several preclinical models of periodontitis, but limitations existed owing to the small size of the periodontal defects in small animals and the insufficient defect status to represent severe human periodontitis $(2,7,35)$. We used beagle dogs' birooted teeth, premolars and molars, because the oral and maxillofacial region of beagle dogs represents that of humans. The canine premolars resemble human molars morphologically and the size of the roots is similar to humans. The defect was surgically made to separate one of the two roots from the surrounding alveolar bone, indicating blood supply and cell migration was limited. Dental rubber impression material was used for induction of intentional inflammation, as the remnant of impression material often makes local periodontitis in daily dental clinics $(18,19,36,40)$. Proven by measured clinical indices, the chosen periodontitis inducer successfully made chronic inflammation inside the infrabony defect in this study

Table 2. Volume Ratio of micro-CT Reconstructed Newly Formed Bone

\begin{tabular}{lccc}
\hline & $\begin{array}{c}\mathrm{BV} \\
\left(\mathrm{mm}^{3}\right)\end{array}$ & $\begin{array}{c}\mathrm{TV} \\
\left(\mathrm{mm}^{3}\right)\end{array}$ & $\begin{array}{c}\text { BV/TV } \\
(\%)\end{array}$ \\
\hline PDLSCs & 206.3 & 249.6 & $82.8 \pm 7.9$ \\
DPSCs & 129.9 & 257.2 & $50.8 \pm 9.6$ \\
PAFSCs & 177.4 & 257.2 & $69.2 \pm 11.1$ \\
Control (no graft) & 127.3 & 264.4 & $47.9 \pm 13.4$ \\
\hline
\end{tabular}

The numbers of analyzed dogs were 8 per group. Values are shown as mean $\pm \mathrm{SD}(\%)$. BV: new bone volume, TV: total bone volume, $\mathrm{BV} / \mathrm{TV}$ : relative bone volume.
(Table 1). Besides, the induced advanced periodontitis did not recover without any treatment after 8 weeks, implicating the disease model size was critical. This new periodontitis model mimicked the advanced periodontitis involved root in humans, where tooth extraction was indicated clinically (60). It provided an appropriate model for testing aDSCs' own ability for periodontal regeneration, although no animal model is identical to the clinical disease state, as numerous etiological factors effect pathogenesis of periodontitis.

Based on the prevailed clinical concepts known as guided tissue regeneration (GTR), some clinicians recommended the use of some biomaterials as a barrier for the periodontal regeneration, in order to prevent apical downgrowth of epithelium. The barriers were known to prevent granulation tissue from reaching contact with the roots during healing $(17,25)$. Epithelial downgrowth interrupted formation of a new connective tissue attachment by preventing repopulation of the cells derived from the periodontal ligament $(33,34,46)$. However, the grafted aDSCs directly covered the root surface in this study and might recruit neighboring mesenchymal progenitor cells, so they prevented epithelial cells from approaching the denuded root surface ahead. One of the known important factors for connective tissue attachment was the space created under the mucoperiosteal flap (33). It has been shown repeatedly that the amount of bone regeneration and connective tissue attachment is dependent of the available space. Although scaffolds and membranes were not used in this study, some space between the denuded tooth root and the mucoperiosteal flap was created by the proper number of aDSCs in the cellular pellet. Besides, the number of the grafted MSCs should be more than that of epithelial cells so that proliferation rate could be higher. Therefore, regeneration of periodontium was progressed without the significant effect of epithelial downgrowth in this study.

Prevention of granulation tissue formation is also an important factor for periodontal regeneration. The possible mechanism of aDSCs could be immunonodulatory and anti-inflammatory effect of MSCs (63). Recently, several studies have reported that treatment with human bone marrow- or adipose-derived MSCs exhibit early efficacy in attenuating the progression of several experimental inflammatory diseases in murine models (2224,56,62). The positive treatment effects of human MSCs on these murine disease models could be due to their inherent capabilities to harness inflammatory cell infiltration, suppress inflammatory mediator production, and/or regulate immune tolerance by increasing the production of anti-inflammatory cytokines. This effect may also influence inhibition of granulation tissue formation and regeneration of healthy periodontal tissues. The negative control group in this study also proved the con- 
A

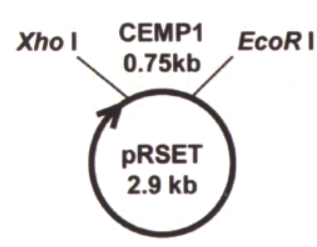

E rhCEMP1

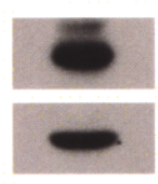

Anti-CEMP1

Anti-His
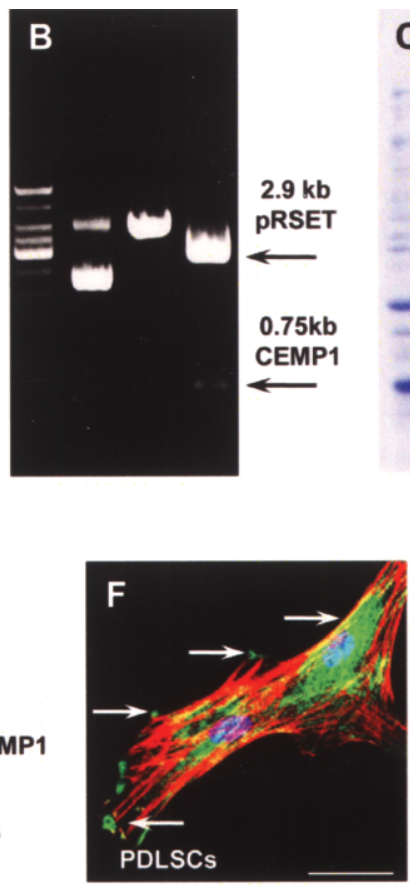

H
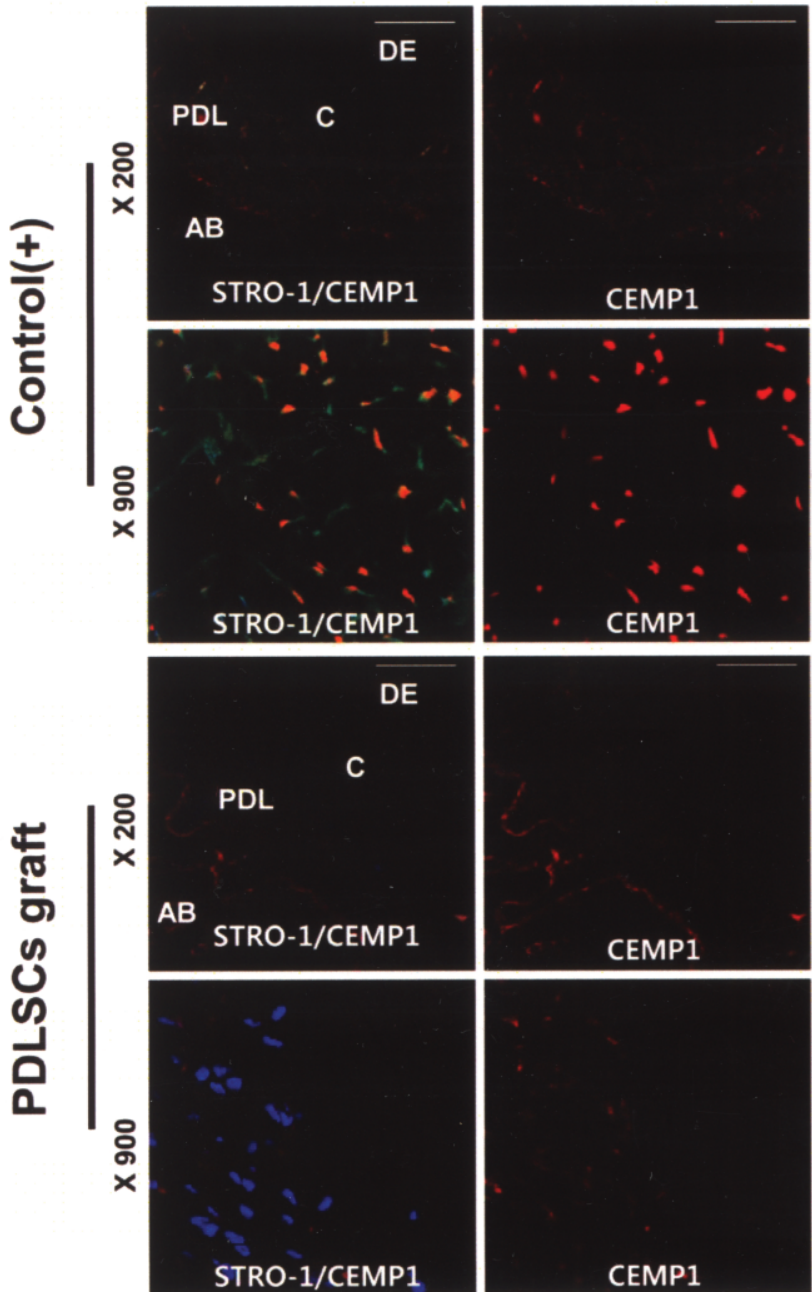

STRO-1/CEMP1

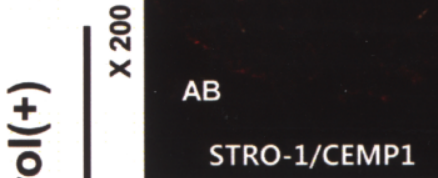

ํํㅇ

\begin{tabular}{l}
8 \\
\hline \\
$\times$
\end{tabular}

STRO-1/CEMP1
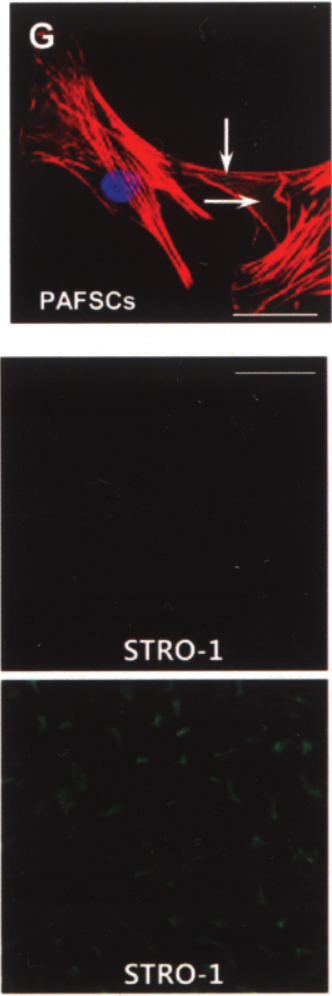

rhCEMP1

30 kDa
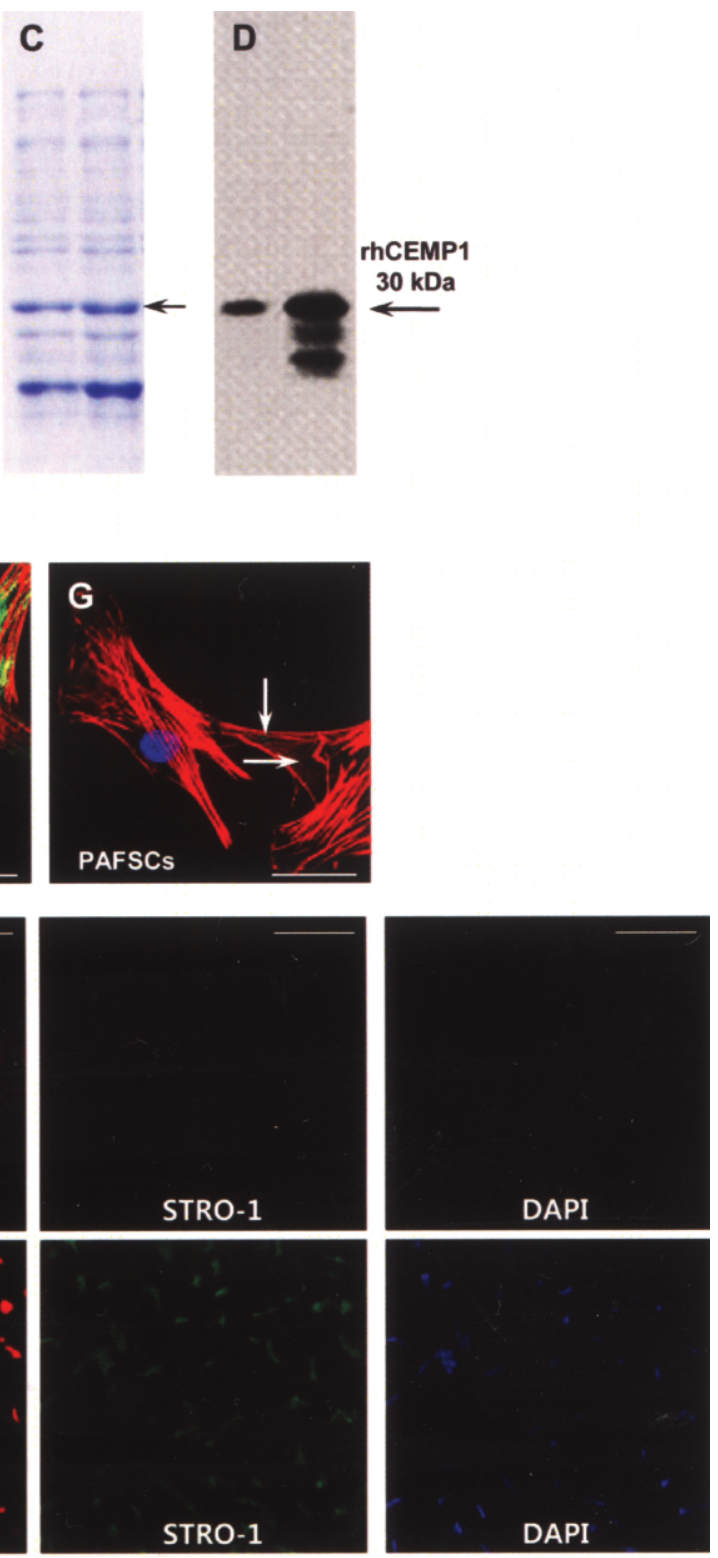

STRO-1

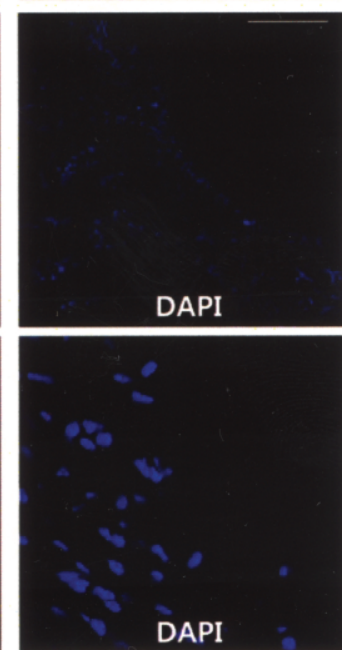




\section{FACING PAGE}

Figure 6. Generation of anti-rhCEMP1 ab and immunolocalization. (A) Design of recombinant vector of CEMP1 PCR transcript with pRSET vector for inducible bacterial protein expression. (B) The insert CEMP1 DNA size 0.75 kb was shown by double restriction enzyme cutting, XhoI and EcoRI, in 1\% argarose gel. (C) The rhCEMP1 expression was induced (right lane) by $1.0 \mathrm{mM}$ IPTG and Coomassie blue-stained gel showed the thicker band at size $30 \mathrm{kDa}$. (D) Immunoblotting with anti-His Ab confirmed the existence of His-tagged rhCEMP1 protein in the IPTG-induced condition (right lane). (E) Immunoblotting of induced bacterial blunt lysate with anti-His antibody and anti-rhCEMP1 polyclonal antibody. Purified anti-rhCEMP1 antibody showed immunospecificity with $30 \mathrm{kDa}$ size rhCEMP1 protein. (F, G) Immunolocalization of rhCEMP1 in dental stem cells showed more positive staining in the cytosole of PDLSCs than in the PAFSCs (white arrows). Scale bars: $20 \mu \mathrm{m}$. (H) CEMP1 was stained strongly at the cementoid phase, inside the PDL space especially areas near alveolar bone, while alveolar bone and dentin were largely negative. The extent of STRO-1-positive cells in the normal PDL space showed MSCs exist in the normal PDL space (upper panels). The extent of CEMP1 expression was less but positive in the regenerated cementum and PDL, but especially strong in PDL space near alveolar bone. STRO-1 expression was decreased in the regenerated PDL. Scale bars: $400 \mu \mathrm{m}$. Abbreviations: AB, alveolar bone; DE, dentin; C,cementum; PDL, periodontal ligament.

trary, as the periodontal defect without aDSCs graft showed root resorption followed by chronic inflammation (Fig. 4B, upper right panel and 4D, lower right panel) (33).

Cementum is the third dental mineralized tissue in the human body, followed by enamel and dentin. This hard tissue exists around the tooth root and provides the interface through which the root surface is anchored to the collagen Sharpey's fibers of the periodontal ligament $(12,44)$. The importance of cementum regeneration is emphasized in previous studies as formation of new cementum with newly inserted Sharpey's fibers on root surface is a prerequisite and a crucial step in the regeneration of periodontal tissues (54). The recent evidence indicates that cementum formation is critical for appropriate maturation of the peirodontium, both during development as well as that associated with regeneration of periodontal tissues (50). However, one major impediment to identify the new cementum regeneration and to understand the molecular mechanisms that regulated periodontal regeneration is the lack of cementum markers $(1,6)$. Several cementum-related proteins were suggested as a cementum marker, such as collagen type I and III (12), fibronectin, osteopotin, bone sialoprotein, osteocalcin, vitronectin, and growth factors such as TGF- $\beta$ and BMP-2 (43,54). However, these molecules are not cementum-specific. Cementum attachment protein (CAP) and cementum protein (CP) were identified later as cementum-specific proteins but their antibodies recognized alveolar bone cells and dental folliclederived cells as well as the cells in the cementoid layer and PDL space $(3-5,38,47,52)$. We confirmed periodontal tissue regeneration using anti-rhCEMP1 antibody, which was reported as a cementum and periodontal ligament specific protein (43). Its expression was known as confined to the subpopulations in periodontal ligament and cementoblasts and the same distribution was observed in the normal canine periodontium in this study (Fig. 6H, upper two lines). The rhCEMP1 expression in the regenerated periodontium was not as strong as in the normal control, but positive in the cementoid and PDL space (Fig. 6H, lower two lines). These results confirmed that PDLSCs and PAFSCs regenerated the new cementum, although the tissue should be matured for a longer period of time. As the number of STRO-1-positive MSCs decreased 2 months after the aDSCs graft when a large number of DAPI-stained cells still exist in the regenerated area, it is suggested that the grafted MSCs may differentiate into cementoblasts, which contributed to production of cementoid layer and embedding Sharpey's fibers.

We report here that transplanted autologous PDLSCs and PAFSCs generated new cementum and Sharpey's fiber of periodontal ligament as well as the alveolar bone in the advanced periodontitis model in beagle dogs. We suggest autologous PDLSCs as the best candidate for the future clinical application in the treatment of perioodntitis, as it showed best result with respect to the quality and the quantity of the regenerated tissue. Further studies are necessary to investigate which cytokines from aDSCs influence stabilization and differentiation of diseased periodontal microenvironment and which factors make three kinds of dental stem cells react differently in vivo. Besides, the role of CEMP1 in regenerated periodontium and developing tooth root should be elucidated in the future study.

ACKNOWLEDGMENTS: This work was supported by the grants from the National Research Foundation of Korea (NRF) grant funded by the Korea government (MEST) (No. 2009-0066366) to Pill-Hoon Choung.

\section{REFERENCES}

1. Alvarez-Perez, M. A.; Narayan, S.; Zeichner-David, M.; Carmona, B. R.; Arzate, H. Molecular cloning, expression and immunolocalization of a novel human cementumderived protein (CP-23). Bone 38:409-419; 2006.

2. Araújo, M. G.; Berglundh, T.; Lindhe, J. On the dynamics of periodontal tissue formation in degree III furcation defects. An experimental study in dogs. J. Clin. Periodontol. 24:738-746; 1997. 
3. Arzate, H.; Jiménez-García, L. F.; Alvarez-P?rez, M. A.; Landa, A.; Bar-Kana, I.; Pitaru, S. Immunolocalization of a human cementoblastoma conditioned medium-derived protein. J. Dent. Res. 81:541-546; 2002.

4. Arzate, H.; Olson, S. W.; Page, R. C.; Gown, A. M.; Narayanan, A. S. Production of a monoclonal antibody to an attachment protein derived from human cementum. FASEB J. 6:2990-2995; 1992.

5. Bar-Kana, I.; Narayan, A. S.; Savion, N.; Pitaru, S. Cementum attachment protein is restricted to the mineralized tissue forming cells of the periodontium. Eur. J. Oral Sci. 106(Suppl. 1):357-364; 1998.

6. Bosshardt, D. D. Are cementoblasts a subpopulation of osteoblasts or a unique phenotype? J. Dent. Res. 84:390406; 2005.

7. Camargo, P. M.; Lekovic, V.; Weinlaender, M.; DivnicResnik, T.; Pavlovic, M.; Kenney, E. B. A surgical reentry study on the influence of platelet-rich plasma in enhancing the regenerative effects of bovine porous bone mineral and guided tissue regeneration in the treatment of intrabony defects in humans. J. Periodontol. 80:915-923; 2009.

8. Camelo, M.; Nevins, M. L.; Lynch, S. E.; Schenk, R. K.; Simion, M.; Nevins, M. Periodontal regeneration with an autogenous bone-Bio-Oss composite graft and a Bio-Gide membrane. Int. J. Periodontics Restor. Dent. 21:109-119; 2001.

9. Chang, C. J.; Yen, M. L.; Chen, Y. C.; Chien, C. C.; Huang, H. I.; Bai, C. H.; Yen, B. L. Placenta-derived multipotent cells exhibit immunosuppressive properties that are enhanced in the presence of interferon. Stem Cells 24:2466-2477; 2006.

10. Chen, Y. L.; Chen, P. K.; Jeng, L. B.; Huang, C. S.; Yang, L. C.; Chung, H. Y.; Chang, S. C. Periodontal regeneration using ex vivo autologous stem cells engineered to express the BMP-2 gene: An alternative to alveolaplasty. Gene Ther. 15:1469-1477; 2008.

11. Christgau, M.; Moder, D.; Hiller, K. A.; Dada, A.; Schmitz, G. Growth factors and cytokines in augologous platelet concentrate and their correlation to periodontal regeneration outcomes. J. Clin. Periodontol. 33:837-845; 2006.

12. Christner, P.; Robinson, R.; Clark, C. C. A preliminary characterization of human cementum to collagen. Calcif. Tissue Res. 28:147-150; 1997.

13. Covas, D. T.; Panepucci, R. A.; Fontes, A. M.; Silva, Jr., W. A.; Orellana, M. D.; Freitas, M. C.; Neder, L.; Santos, A. R.; Peres, L. C.; Jamur, M. C.; Zago, M. A. Multipotent mesenchymal stromal cells obtained from diverse human tissues share functional properties and geneexpression profiles with CD146+ perivascular cells and fibroblasts. Exp. Hematol. 36:642-654; 2008.

14. Crea, A.; Dassatti, L.; Hoffmann, O.; Zafiropoulos, G. G.; Deli, G. Treatment of intrabony defects using guided tissue regeneration or enamel matrix derivative: A 3-year prospective randomized clinical study. J. Periodontol. 79: 2281-2289; 2008.

15. Demir, B.; Sengun, D.; Berberolu, A. Clinical evaluation of platelet-rich plasma and bioactive glass in the treatment of intrabony defects. J. Clin. Periodontol. 34:709-715; 2007.

16. Eickholz, P.; Hörr, T.; Klein, F.; Hassfeld, S.; Kim, T. S. Radiographic parameters for prognosis of periodontal healing of infrabony defects: Two different definitions of defect depth. J. Periodontol. 75:399-407; 2004.
17. Eickholz, P.; Lenhard, M.; Benn, D. K.; Staehle, H. J. Periodontal surgery of vertical bony defects with or without synthetic bioabsorbable barriers. 12-month results. J. Periodontol. 69:1210-1217; 1998.

18. Elíasson, S. T.; Holte, N. O. Rubber-base impression material as a foreign body. Report of a case. Oral Surg. Oral Med. Oral Pathol. 48:379-380; 1979.

19. Evans, G. H. Rubber base impression material. Oral Surg. Oral Med. Oral Pathol. 70:523; 1990.

20. Flemming, T. F. Periodontitis. Ann. Periodontol. 4:32-38; 1999.

21. Geffner, L. F.; Santacruz, P.; Izurieta, M.; Flor, L.; Maldonado, B.; Auad, A. H.; Montenegro, X.; Gonzalez, R.; Silva, F. Administration of autologous bone marrow stem cells into spinal cord injury patients via multiple routes is safe and improves their quality of life: Comprehensive case studies. Cell Transplant. 17:1277-1293; 2008.

22. González, M. A.; Gonzalez-Rey, E. P.; Rico, L.; Büscher, D.; Delgado, M. Adipose-derived mesenchymal stem cells alleviate experimental colitis by inhibiting inflammatory and autoimmune responses. Gastroenterology 136:978989; 2009.

23. Gonzaález, M. A.; Gonzalez-Rey, E. P.; Rico, L.; Büscher, D.; Delgado, M. Treatment of experimental arthritis by inducing immune tolerance with human adiposederived mesenchymal stem cells. Arthritis Rheum. 60: 1006-1019; 2009.

24. Gonzalez-Rey, E. P.; Anderson, P.; González, M. A.; Rico, L.; Büscher, D.; Delgado, M. Human adult stem cells derived from adipose tissue protect against experimental colitis and sepsis. Gut 58:929-939; 2009.

25. Gottlow, J.; Nyman, S.; Kaning, T.; Lindhe, J. New attachment formation as the result of controlled tissue regeneration. J. Clin. Periodontol. 11:494-503; 1984.

26. Gronthos, S.; Brahim, J.; Li, W.; Fisher, L. W.; Cherman, N.; Boyde, A.; DenBesten, P.; Robey, P. G.; Shi, S. Stem cell properties of human dental pulp stem cells. J. Dent. Res. 81:531-535; 2002.

27. Gronthos, S.; Mankani, M.; Brahim, J.; Robey, P. G.; Shi, S. Postnatal human dental pulp stem cells (DPSCs) in vitro and in vivo. Proc. Natl. Acad. Sci. USA 97:1362513630; 2000.

28. Hanna, R.; Trejo, P. M.; Weltman, R. L. Treatment of intrabony defects with bovine-derived xenograft alone and in combination with platelet-rich plasma: A randomized clinical trial. J. Periodontol. 75:1668-1677; 2004.

29. Harlow, E. D.; Lane, D. Antibodies; a laboratory manual. New York: Cold Spring Harbor Laboratory; 1988.

30. Heins, P.; Avriett, A.; Chace, Sr., R.; Hartigan, M. Onewall proximal defects: Pretreatment characteristics and bone response following flap curettage. J. Clin. Periodontol. 17:282-287; 1990.

31. Jepsen, S.; Eberhard, J.; Herrera, D.; Needleman, I. A systematic review of guided tissue regeneration for periodontal furcation defects. What is the effect of guided tissue regeneration compared with surgical debridement in the treatment of furcation defects? J. Clin. Periodontol. 29: 103-116, discussion 160-162; 2002.

32. Jo, Y. Y.; Lee, H. J.; Kook, S. Y.; Choung, H. W.; Park, J. Y.; Chung, J. H.; Choung, Y. H.; Seo, B. M.; Yang, H. C.; Choung, P. H. Isolation and characterization of postnatal stem cells from human dental tissues. Tissue Eng. 13:767-773; 2007.

33. Karring, T.; Nyman, S.; Gottlow, J.; Laurell, L. Develop- 
ment of the biological concept of guided tissue regeneration-animal and human studies. Periodontol. 2000 1:2635; 1993.

34. Karring, T.; Nyman, S.; Lindhe, J. Healing following implantation of periodontitis affected roots into bone tissue. J. Clin. Periodontol. 7:96-105; 1980.

35. Keles, G. C.; Cetinkaya, B. O.; Baris, S.; Albayrak, D.; Simsek, S. B. Comparison of platelet pellet with or without guided tissue regeneration in the treatment of class II furcation defects in dogs. Clin. Oral Investig. 13:393-400; 2009.

36. Kent, W. A.; Shillingburg, Jr., H. T.; Tow, H. D. Impression material foreign body: Report of a case. Quintessence Int. 19:9-11; 1988.

37. Lindroos, B. K.; Mäenpää, K.; Ylikomi, T.; Oja, H.; Suuronen, R.; Miettinen, S. Characterisation of human dental stem cells and buccal mucosa fibroblasts. Biochem. Biophys. Res. Commun. 368:329-335; 2009.

38. Liu, H. W.; Yacobi, R.; Savion, N.; Narayanan, A. S.; Pitaru, S. A collagenous cementum-derived attachment protein is a marker for progenitors of the mineralized tissue-forming cell lineage of the periodontal ligament. J. Bone Miner. Res. 12:1691-1699; 1997.

39. Liu, Y.; Zheng, Y.; Ding, G.; Fang, D.; Zhang, C.; Bartold, P. M.; Gronthos, S.; Shi, S.; Wang, S. Periodontal ligament stem cell-mediated treatment for periodontitis in miniature swine. Stem Cells 26:1065-1073; 2008.

40. Matthew, I. R.; Browne, R. M.; Frame, J. W.; Millar, B. G. Subperiosteal behaviour of alginate and cellulose wound dressing materials. Biomaterials 164:275-278; 1995.

41. Miura, M.; Gronthos, S.; Zhao, M.; Lu, B.; Fisher, L. W.; Robey, P. G.; Shi, S. SHED: Stem cells from human exfoliated deciduous teeth. Proc. Natl. Acad. Sci. USA 100: 5807-5812; 2003.

42. Morsczeck, C.; Götz, W.; Schierholz, J.; Zeilhofer, F.; Kühn, U.; Möhl, C.; Sippel, C.; Hoffmann, K. H. Isolation of precursor cells (PCs) from human dental follicle of wisdom teeth. Matrix Biol. 24:155-165; 2005.

43. Narayanan, A. S.; Bartold, M. Biochemistry of periodontal connective tissue and their regeneration: A current perspective. Connect. Tissue Res. 34:191-201; 1996.

44. Narayanan, A. S.; Page, R. C. Biochemical characterization of collagens synthesized by fibroblasts derived from normal and diseased human gingiva. J. Biol. Chem. 251: 5464-5471; 1976.

45. Nauta, A. J.; Fibbe, W. E. Immunomodulatory properties of mesenchymal stromal cells. Blood 110:3499-3506; 2007.

46. Nyman, S.; Gottlow, J.; Karring, T.; Lindhe, J. The regenerative potential of the periodontal ligament. An experimental study in the monkey. J. Clin. Periodontol. 9:257$265 ; 1982$.

47. Olson, S.; Arzate, H.; Naraynan, A. S.; Page, R. C. Cell attachment activity of cementum proteins and mechanism of endotoxin inhibition. J. Dent. Res. 70:1272-1277; 1991.

48. Petersen, P. E. Global policy for improvement of oral health in the 21 st century-implications to oral health research of World Health Assembly 2007, World Health Organization. Community Dentist. Oral Epidemiol. 37:1-8; 2009.
49. Petersen, P. E.; Ogawa, H. Strengthening the prevention of periodontal disease: The WHO approach. J. Periodontol. 76:2187-2193; 2005.

50. Pitaru, S.; Narayanan, S. A.; Olson, S.; Savion, N.; Hekmati, H.; Alt, I.; Metzger, Z. Specific cementum attachment protein enhances selectively the attachment and migration of periodontal cells to root surfaces. J. Periodontal Res. 30:360-368; 1995.

51. Pittenger, M. F.; Mackay, A. M.; Beck, S. C.; Jaiswal, R. K.; Douglas, R.; Mosca, J. D.; Moorman, M. A.; Simonetti, D. W.; Craig, S.; Marshak, D. R. Multilineage potential of adult human mesenchymal stem cells. Science 284:143-147; 1999.

52. Saito, M.; Iwase, M.; Maslan, S.; Nozaki, N.; Yamauchi, M.; Handa, K.; Takahashi, O.; Sato, S.; Kawase, T.; Teranaka, T.; Narayanan, A. S. Expresison of cementumderived attachment protein in bovine tooth germ during cementogenesis. Bone 29:242-248; 2001.

53. Sambrook, J.; Russel, W. D. Molecular cloning: A laboratory manual. New York: Cold Spring Harbor Press; 2001.

54. Saygin, N. E.; Giannobile, W. V.; Somerman, M. J. Moelcular and cell biology of cementum. Periodontology 2000 24:73-98; 2000 .

55. Seo, B. M.; Miura, M.; Gronthos, S.; Bartold, P. M.; Batouli, S.; Brahim, J.; Young, M.; Robey, P. G.; Wang, C. Y.; Shi, S. Investigation of multipotent postnatal stem cells from human periodontal ligament. Lancet 364:149$155 ; 2004$.

56. Souza, B. S.; Nogueira, R. C.; de Oliveira, S. A.; de Freitas, L. A.; Lyra, L. G.; Ribeiro dos Santos, R.; Lyra, A. C.; Soares, M. B. Current status of stem cell therapy for liver diseases. Cell Transplant. 18:1261-1279; 2009.

57. Spaeth, E.; Klopp, A.; Dembinski, J.; Andreeff, M.; Marini, F. Inflammation and tumor microenvironments: Defining the migratory itinerary of mesenchymal stem cells. Gene Ther. 15:730-738; 2008.

58. Trombelli, L. Which reconstructive procedures are effective for treating the periodontal intraosseous defect? Periodontology 2000 37:88-105; 2005.

59. Vrotsos, J. A.; Parashis, A. O.; Theofanatos, G. D.; Smulow, J. B. Prevalence and distribution of bone defects in moderate and advanced adult periodontitis. Clin. Periodontol. 26:44-48; 1999.

60. Wu, S. K.; Yeh, H. C.; Chan, C. P. The prevalence and distribution of bone defects in patients with moderate to advanced periodontitis. Chang Gung Med. J. 24:423-430; 2001.

61. Xu, J.; Wang, W.; Kapila, Y.; Lotz, J.; Kapila, S. Multiple differentiation capacity of STRO-1+/CD146+ PDL mesenchymal progenitor cells. Stem Cells Dev. 18:487-496; 2009.

62. Zhang, J.; Li, Y.; Chen, J.; Cui, Y.; Lu, M.; Elias, S. B.; Mitchell, J. B.; Hammill, L.; Vanguri, P.; Chopp, M. Human bone marrow stromal cell treatment improves neurological functional recovery in EAE mice. Exp. Neurol. 195:16-26; 2005.

63. Zhang, Q.; Shi, S.; Liu, Y.; Uyanne, J.; Shi, Y.; Shi, S.; Le, A. D. Mesenchymal stem cells derived from human gingiva are capable of immunomodulatory functions and ameliorate inflammation-related tissue destruction in experimental colitis. J. Immunol. 15:7787-7798; 2009. 
